\title{
SURGICAL MANAGEMENT OF ADENOCARCINOMA OF ESOPHAGOGASTRIC JUNCTION - A TERTIARY CARE CENTRE EXPERIENCE IN SOUTH INDIA
}

\begin{tabular}{|l|lll}
\hline Gastroenterology &
\end{tabular}

Karthikeyan Resident, Institute of Surgical Gastroenterology, Madras Medical College and Rajiv mohan Gandhi Government General Hospital, Chennai, India.

Sivakumar

M.Ch., Assistant professor, Institute of Surgical Gastroenterology, Madras Medical kalyanashanmugam College and Rajiv Gandhi Government General Hospital, Chennai, India.

Prasanna gopal M.Ch., Resident, Institute of Surgical Gastroenterology, Madras Medical College and Rajiv Gandhi Government General Hospital, Chennai, India.

Prabhakaran Raju

M.Ch., MRCS(Glas), Associate professor, Institute of Surgical Gastroenterology, Madras Medical College and Rajiv Gandhi Government General Hospital, Chennai, India.

Rajendran M.Ch., Professor, Institute of Surgical Gastroenterology, Madras Medical College and shanmugasundaram Rajiv Gandhi Government General Hospital, Chennai, India.

Naganath babu obla

M.Ch., FRCS(Edin)FACS, Director and Professor, Institute of Surgical Gastroenterology, lakshmanamoorthy*

Madras Medical College and Rajiv Gandhi Government General Hospital, Chennai, India. * Corresponding Author

\section{ABSTRACT}

OBJECTIVE: The incidence of adenocarcinoma of esophagogastric junction is on the rise. The optimal treatment strategy for these tumours has not been clearly established. The aim of this study is to analyse the clinical presentations, management and outcomes following surgery in patients with adenocarcinoma of the esophagogastric junction presenting to a tertiary care centre in South India.

METHODS:Retrospective analysis of prospectively maintained database was performed. Data of all patients operated for adenocarcinoma of esophagogastric junction was analysed with regards to surgical management and clinico-pathological outcomes.RESULTS:Fifty two patients underwent surgery for esophagogastric junction malignancy in our institution from January 2015 to December 2018 . Among them, type I, type II and type III tumours contributed to 6,16 and 30 patients, respectively. Thirty-four patients $(65.4 \%)$ were male. Mean age of the patients was 57 years. Six patients $(11.5 \%)$ received neoadjuvant therapy. Fourteen patients $(26.9 \%)$ were found to have unresectable or metastatic disease during surgery. Six patients $(11.5 \%)$ underwent multiorgan resection. Mean tumour length was $5.4 \mathrm{~cm}$. Number of lymph nodes retrieved ranged from 2 to 25 . Majority of the patients had stage 3 disease on histopathological examination. Major postoperative morbidity (Clavien Dindo grade $\geq 3$ ) was seen in 9 patients. Reoperation was required in 4 patients. In-hospital mortality rate was $11.53 \%$. On follow up, locoregional recurrence was documented in 5 patients

CONCLUSION: Esophagogastric junction adenocarcinoma is an aggressive malignancy with high incidence of unresectable or metastatic disease. Majority of patients presented with larger tumours and at an advanced stage of the disease leading to poor outcomes.

\section{KEYWORDS}

Adenocarcinoma, Esophagogastric junction, Siewert types, Esophagectomy, Morbidity, Recurrence.

\section{INTRODUCTION}

The incidence of adenocarcinoma of esophagus and esophagogastric junction has shown a dramatic increase since 1970s, particularly in the western countries, whereas that of squamous cell cancer has remained static or has declined. At present, adenocarcinoma accounts for about $60 \%-75 \%$ of all esophageal cancers in several nations [1]. This parallels the rise in incidence of obesity and gastroesophageal reflux disease (GERD), which leads to Barrett's esophagus, an important risk factor for these junctional tumours.

The exact definition of esophagogastric junction cancers has not been clear and have been considered as either gastric or esophageal malignancy in the past. The most widely accepted definition is the one proposed by Siewert et al[2]. He defined these tumours as those having epicentre within $5 \mathrm{~cm}$ proximal or distal to the Z-line and this has been validated by many studies. He further classified these tumours into three types based on the location of epicentre. A similar definition has been adopted by the Union for International Cancer Control (UICC) [3]. The American Joint Committee on Cancer (AJCC) has recently defined these tumours as those with epicentre located within $2 \mathrm{~cm}$ of the esophagogastric junction, in accordance with the Nishi classification proposed by the Japanese Gastric Cancer Association (JGCA) [4,5].

The exact etiology of these tumours is still unclear. GERD, obesity, smoking, alcohol intake and intake of processed meat have been found to be associated with the risk for development of junctional cancers. More cases are being reported from developing countries in recent years due to adoption of the western lifestyle. H.pylori infection, high fibre diet and intake of non-steroidal anti-inflammatory drugs have been thought to confer a protective effect.
Management of esophagogastric junction tumours is challenging. They tend to have a poor prognosis compared to both gastric and esophageal cancers. They involve two contiguous organs and also extend across the diaphragmatic hiatus to involve both thoracic and abdominal cavities. Thus, lymph nodes metastasis from these tumours can involve both mediastinal and abdominal nodal stations. Also, location of these tumours at a critical area results in risk of involvement of adjacent organs or structures necessitating multivisceral resection for their complete removal [6].

Surgery forms the cornerstone for management of these tumours. The goal is complete margin-free resection with radical lymphadenectomy. The location of the tumour and lymph node metastasis are critical factors in determining the appropriate surgical procedure. Minimally invasive surgical approaches have also been used with equivalent success as compared to open surgery[7].

Since majority of these tumours are large and locally advanced at presentation, multimodality therapy including chemotherapy and radiotherapy, in addition to surgery, helps to achieve the treatment goals. At present, there is no clear consensus on the optimal management strategy for these tumours.

The aim of the present study is to evaluate the clinical presentation, investigational workup, surgical management and postoperative outcomes of patients with adenocarcinoma of esophagogastric junction presenting to a tertiary care centre in South India.

\section{METHODS}

\section{Patient population}

This retrospective study was conducted in the Institute of Surgical 
Gastroenterology, Madras Medical College, a tertiary referral centre in South India. The study period was between January 2015 and December 2018. All patients with esophagogastric junction adenocarcinoma who were managed in our institute during the four year period were included in the study. Data was retrieved from prospectively maintained institutional database. Cases with incomplete data were excluded.

\section{Patient evaluation}

All patients were diagnosed using upper gastrointestinal endoscopy and biopsy. Barium swallow was done in patients in whom endoscope was not negotiable across the growth due to severe luminal narrowing. Staging workup included contrast-enhanced computed tomography (CT) of the neck, chest and abdomen. PET-CT was done as per the opinion of the institutional multidisciplinary tumour board. Siewert's classification was used to determine the tumour subtype so as to plan appropriate surgery. If complete endoscopy was not possible, classification was done based on findings of barium swallow or CT scan. Staging laparoscopy was done in all patients at the time of definite surgical procedure.

Neoadjuvant chemotherapy with or without radiotherapy was given based on the local extent of the tumour as decided by the multidisciplinary tumour board. Re-evaluation was done with endoscopy and CT scan about 6-8 weeks after completion of neoadjuvant treatment to assess for response. Only those patients without evidence of distant metastasis on imaging were taken up for surgery.

\section{Surgical approach}

Surgical procedure performed was based on the Siewert subtypes. Minimally invasive approach was used based on the performance status of the patients and the surgeons' expertise. Those belonging to Siewert type I tumours underwent transhiatal or minimally invasive esophagectomy with cervical esophagogastric anastomosis. Those with Siewert type II tumours underwent transhiatal/minimally invasive esophagectomy or extended total gastrectomy based on the extent of esophageal and gastric involvement, followed by cervical intrathoracic or intraabdominal anastomosis as appropriate. All those belonging to Siewert type III tumours underwent extended total gastrectomy and esophagojejunal anastomosis.

A minimum of $4-5 \mathrm{~cm}$ proximal and distal in vivo margin was provided in all patients. Feeding jejunostomy was done routinely for early initiation of postoperative enteral nutrition. A minimum of abdominal and lower mediastinal lymph node dissection was done in all patients. Multivisceral resection was done if complete removal of tumour was possible. If tumours were found inoperable or metastatic at surgery, feeding jejunostomy was done and these patients were referred for palliative therapy.

\section{Postoperative management}

Postoperatively, all patients who underwent resection were managed in the intensive care unit until recovery from anaesthesia and withdrawal from ventilator support. Jejunostomy feeds were started on $2^{\text {nd }}$ or $3^{\text {rd }}$ postoperative day. Orals were gradually started when there was no evidence of anastomotic leak as evidenced by clinical examination or using water-soluble contrast study.

Postoperative complications were graded as per the Clavien-Dindo classification system and managed accordingly. Patients were discharged when they were able to take adequate oral nutrition.

Adjuvant therapy was given based on the histopathological analysis of resected specimen as appropriate. Patients were followed up in the outpatient department every 3-6 monthly, and endoscopy and/or CT scan were done as clinically indicated. Recurrences, if detected, were managed as per the decision of the multidisciplinary team.

\section{Statistical analysis}

The baseline patient characteristics, surgical procedures performed, postoperative morbidity and mortality, histopathological staging and pattern of recurrences were analysed in this study. Data was expressed as mean ( \pm standard deviation) or percentage. Parameters were compared using Chi-square test and one-way ANOVA. Statistical analysis was done using SPSS software and a p-value of less than 0.05 was considered statistically significant

\section{RESULTS}

Fifty-two patients underwent surgery for esophagogastric junction adenocarcinoma in our institution during the four-year study period. Thirty-four patients (65.4\%) were male. Mean age of the patients was 57 years (see Figure 1). More than half of them belonged to Siewert III subtype $(n=30)$. Only a minority $(11.5 \% ; n=6)$ received neoadjuvant therapy. (see Table 1 )

\section{Table 1: Baseline patient characteristics}

\begin{tabular}{|c|c|c|c|c|c|}
\hline & $\begin{array}{c}\text { Siewert } \\
\text { type I } \\
(n=6)\end{array}$ & $\begin{array}{l}\text { Siewert } \\
\text { type II } \\
(\mathrm{n}=16)\end{array}$ & $\begin{array}{c}\text { Siewert } \\
\text { type III } \\
(\mathrm{n}=30)\end{array}$ & $\begin{array}{c}\text { Total } \\
(n=52)\end{array}$ & \begin{tabular}{|c|}
$p$ \\
value
\end{tabular} \\
\hline Incidence & $11.5 \%$ & $30.8 \%$ & $57.7 \%$ & - & \\
\hline $\mathrm{M}: \mathrm{F}$ & $1: 1$ & $15: 1$ & $1.14: 1$ & $1.9: 1$ & 0.02 \\
\hline $\begin{array}{l}\text { Age in years } \\
\text { (Mean } \pm \text { S.D.) }\end{array}$ & $62.3 \pm 6.6$ & $58.9 \pm 12.1$ & $54.5 \pm 10.9$ & $56.8 \pm 11.1$ & 0.19 \\
\hline Comorbidities & $1(16.7 \%)$ & $5(31.3 \%)$ & $6(20 \%)$ & $12(23 \%)$ & 0.64 \\
\hline $\begin{array}{c}\text { WHO } \\
\text { Performance } \\
\text { status }\end{array}$ & & & & & \\
\hline $\begin{array}{l}\text { PS } 0 \\
\text { PS } 1\end{array}$ & $\begin{array}{c}1(16.7 \%) \\
3(50 \%)\end{array}$ & $\begin{array}{c}2(12.5 \%) \\
8(50 \%)\end{array}$ & $\begin{array}{c}3(10 \%) \\
14(46.7 \%)\end{array}$ & $\begin{array}{c}6(11.5 \%) \\
25(48.1 \%)\end{array}$ & $\begin{array}{l}0.88 \\
0.97\end{array}$ \\
\hline PS 2 & $2(33.3 \%)$ & $6(37.5 \%)$ & $13(43.3 \%)$ & $21(40.4 \%)$ & 0.87 \\
\hline $\begin{array}{c}\text { Neoadjuvant } \\
\text { therapy }\end{array}$ & 0 & $3(18.8 \%)$ & $3(10 \%)$ & $6(11.5 \%)$ & 0.40 \\
\hline $\begin{array}{l}\text { Metastatic } \\
\text { disease }\end{array}$ & $1(16.7 \%)$ & $4(25 \%)$ & $5(16.7 \%)$ & $10(19.2 \%)$ & 0.78 \\
\hline $\begin{array}{c}\text { Unresectable } \\
\text { disease }\end{array}$ & 0 & $2(12.5 \%)$ & $2(6.7 \%)$ & $4(7.7 \%)$ & 0.50 \\
\hline
\end{tabular}

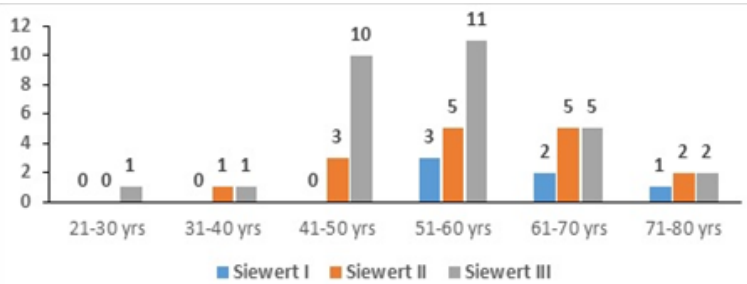

\section{Figure 1: Age distribution}

All patients underwent staging laparoscopy which detected liver and/or peritoneal metastasis in 10 patients $(19.2 \%)$. Four patients $(7.7 \%)$ were found to have unresectable disease at surgery. Six patients $(11.5 \%)$ underwent multiorgan resection and most of them $(n=5)$ belonged to Siewert type III group. Thoracotomy for intrathoracic anastomosis was needed in 3 patients. Intraoperative blood transfusion was needed in 22 out of the 38 patients $(58 \%)$ who underwent resection, with majority belonging to Siewert type III group. (see Table 2)

\section{Table 2: Surgical procedures performed}

\begin{tabular}{|c|c|c|c|c|}
\hline & $\begin{array}{c}\text { Siewert } \\
\text { type I } \\
(\mathbf{n = 6})\end{array}$ & $\begin{array}{c}\text { Siewert } \\
\text { type II } \\
(\mathbf{n = 1 6 )}\end{array}$ & $\begin{array}{c}\text { Siewert } \\
\text { type III } \\
(\mathbf{n = 3 0 )}\end{array}$ & $\begin{array}{c}\mathbf{p} \\
\text { value }\end{array}$ \\
\hline $\begin{array}{c}\text { Curative intent (n=38) } \\
\text { Transhiatal esophagectomy }\end{array}$ & 4 & 2 & 0 & \\
$\begin{array}{c}\text { VATS assisted esophagectomy } \\
\text { Extended total gastrectomy }\end{array}$ & 0 & 1 & 0 & - \\
\hline Multivisceral resection & 0 & $1(10 \%)$ & $5(21.7 \%)$ & 0.32 \\
\hline $\begin{array}{c}\text { Intrathoracic anastomosis } \\
\text { by thoracotomy }\end{array}$ & 0 & $1(10 \%)$ & $2(8.7 \%)$ & 0.95 \\
\hline $\begin{array}{c}\text { Palliative intent (n=14) } \\
\text { Feeding jejunostomy }\end{array}$ & $1(16.7 \%)$ & $6(37.5 \%)$ & $7(23.3 \%)$ & 0.49 \\
\hline
\end{tabular}

Among those who underwent definitive resection $(n=38)$, major postoperative morbidity (Clavien Dindo grade $\geq 3$ ) was seen in 9 patients $(23.7 \%)$, namely conduit necrosis $(n=1)$, need for tracheostomy $(n=4)$, intrathoracic anastomotic leak $(n=2)$, FJ site leak $(\mathrm{n}=1)$ and intraabdominal abscess $(\mathrm{n}=1)$. Prolonged ventilator support for more than 48 hours was needed in 6 patients. Reoperation was required in 4 patients $(7.7 \%)$. In-hospital mortality occurred in 6 patients (11.5\%). (see Table 3 )

On histopathological analysis of resected specimen, the mean tumour length was $5.4 \mathrm{~cm}$. Number of lymph nodes (LNs) retrieved ranged from 2 to 25 (median: 8). Majority of the patients had stage IIIB disease 
$(\mathrm{n}=18 ; 47.4 \%)$ followed by stage IVA disease $(\mathrm{n}=13 ; 34.2 \%)$. (see Table 4).

Recurrence was documented in 5 patients $(15.6 \%)$ during a median follow up of 23 months (6-38 mths). One patient had both regional and distant recurrence. (see Table 5)

Table 3: Postoperative outcomes

\begin{tabular}{|c|c|c|c|c|c|}
\hline & $\begin{array}{c}\text { Siewert } \\
\mathbf{I} \\
(\mathrm{n}=\mathbf{5})\end{array}$ & $\begin{array}{r}\text { Siewert I } \\
(\mathrm{n}=10)\end{array}$ & $\begin{array}{c}\text { Siewert } \\
\text { III } \\
(\mathrm{n}=\mathbf{2 3})\end{array}$ & $\begin{array}{c}\text { Total } \\
(\mathrm{n}=\mathbf{3 8})\end{array}$ & $\begin{array}{c}\mathbf{p} \\
\text { value }\end{array}$ \\
\hline $\begin{array}{c}\text { Mechanical } \\
\text { ventilation }>48 \mathrm{hr}\end{array}$ & $1(20 \%)$ & $2(20 \%)$ & $3(13 \%)$ & $6(15.8 \%)$ & 0.85 \\
\hline $\begin{array}{c}\text { Overall } \\
\text { complicatio }\end{array}$ & $3(60 \%)$ & $5(50 \%)$ & $8(34.8 \%)$ & $16(42.1 \%)$ & 0.49 \\
\hline Anastomotic leak & $1(20 \%)$ & $2(20 \%)$ & $1(4.3 \%)$ & $4(10.5 \%)$ & \\
\hline Cor & $1(20 \%)$ & - & - & $1(2$. & \\
\hline Carc & $1(20 \%)$ & $3(30 \%)$ & $4(17.4 \%)$ & $8(21$ & \\
\hline Vocal c & $1(20 \%)$ & & - & $1(2.6 \%)$ & \\
\hline Wou & . & 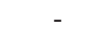 & $2(8.7$ & & \\
\hline Duodenal $t$ & - & $1(10 \%)$ & $1(4.3 \%)$ & $2(5.3 \%)$ & \\
\hline $\begin{array}{l}\text { Major morbidity } \\
\text { (Clavien Dindo } \\
\geq 3 \text { ) }\end{array}$ & $2(40 \%)$ & $4(40 \%)$ & $3(13 \%)$ & $9(23.7 \%)$ & 0.16 \\
\hline $\begin{array}{c}\text { Hospital stay in } \\
\text { days (Mean } \pm \text { S.D.) }\end{array}$ & $11 \pm 2$ & $12 \pm 2$ & $14 \pm 4$ & $13 \pm 4$ & 0.12 \\
\hline Reoperati & $1(20 \%)$ & $1(10 \%)$ & $2(8.7 \%)$ & $4(10.5 \%)$ & 0.76 \\
\hline $\begin{array}{c}\text { In-hospital } \\
\text { mortality }\end{array}$ & $1(20 \%)$ & $3(30 \%)$ & $2(6.7 \%)$ & $6(15.8 \%)$ & 0.2 \\
\hline
\end{tabular}

Table 4: Pathological analysis

\begin{tabular}{|c|c|c|c|c|c|}
\hline & $\begin{array}{c}\text { Siewert I } \\
(\mathbf{n}=5)\end{array}$ & $\begin{array}{c}\text { Siewert II } \\
(\mathbf{n}=\mathbf{1 0})\end{array}$ & $\begin{array}{c}\text { Siewert III } \\
(\mathbf{n}=\mathbf{2 3})\end{array}$ & $\begin{array}{c}\text { Total } \\
(\mathbf{n}=\mathbf{3 8})\end{array}$ & $\begin{array}{c}\mathbf{p} \\
\text { value }\end{array}$ \\
\hline $\begin{array}{c}\text { Mean tumour } \\
\text { length (cm) }\end{array}$ & $5 \pm 1.6$ & $5.5 \pm 1.2$ & $5.4 \pm 1.5$ & $5.4 \pm 1.4$ & 0.81 \\
\hline Mean LNs & $7(2-10)$ & $9(3-21)$ & $8(2-25)$ & $8(2-25)$ & 0.73 \\
dissected (range) & & & & & \\
\hline AJCC Stage IC & 1 & 1 & 1 & 3 & 0.48 \\
Stage IIB & 2 & 0 & 2 & 4 & 0.07 \\
Stage IIIB & 2 & 6 & 10 & 18 & 0.64 \\
Stage IVA & 0 & 3 & 10 & 13 & 0.73 \\
\hline Differentiation & & & & & \\
Grade 1 & 0 & 1 & 2 & 3 & 0.90 \\
Grade 2 & 4 & 7 & 8 & 19 & 0.06 \\
Grade 3 & 1 & 2 & 13 & 16 & 0.08 \\
\hline R0 resection & $100 \%$ & $100 \%$ & $95.7 \%$ & $97.4 \%$ & 0.82 \\
R1 resection (n) & 0 & 0 & $4.3 \%(1)$ & $2.6 \%$ & \\
\hline
\end{tabular}

Table 5: Pathological analysis

\begin{tabular}{|c|c|c|c|c|}
\hline Site of recurrence & $\begin{array}{c}\text { Siewert } \\
\text { I (n=4) }\end{array}$ & $\begin{array}{c}\text { Siewert II } \\
(\mathbf{n}=\mathbf{7})\end{array}$ & $\begin{array}{c}\text { Siewert } \\
\text { III (n=21) }\end{array}$ & $\mathbf{p}$ value \\
\hline Loco-regional only & $1(25 \%)$ & $2(28.6 \%)$ & $1(4.8 \%)$ & 0.42 \\
\hline Locoregional + distant & 0 & 0 & $1(4.8 \%)$ & \\
\hline
\end{tabular}

\section{DISCUSSION}

Though the incidence of esophagogastric junction adenocarcinoma is documented to be on the rise in western countries, there is paucity of such data from the Indian subcontinent. A retrospective study from south India could not demonstrate any discernible time trends in the incidence of junctional adenocarcinoma over a 16 year period [8]. However, another retrospective analysis demonstrated a trend towards an increase in the incidence of adenocarcinoma involving the esophagogastric junction over a similar time period[9]

In our study, majority of the patients belonged to Siewert type III $(57.7 \%)$ and II $(30.8 \%)$ and only $11.5 \%$ of the patients had Siewert type I tumours. The incidence of the three subtypes has been reported to be similar in Western studies but most tumours in the East are Siewert types II and III, as seen in this study. This is attributed to higher prevalence of reflux related conditions in the West [10].

The mean age at presentation was 57 years. Most patients belonged to $5^{\text {th }}$ to $7^{\text {th }}$ decades of life. There was a progressive decrease in mean age from Siewert I to Siewert III subtypes, which however did not reach statistical significance. This is in contrast to a large study involving more than 1600 patients, which reported no significant age difference between the three types [6]. This may be attributed to variable number of patients in each group. Forty percent of patients in Siewert III group and $25 \%$ of patients in Siewert II group belonged to $3^{\text {rd }}-5^{\text {th }}$ decades of life in this study.

Twenty-three percent of patients had comorbidities like diabetes mellitus, systemic hypertension, coronary artery disease, previously treated pulmonary tuberculosis, and chronic kidney disease. Almost half of all male patients were chronic smokers. Almost all patients presented with some degree of dysphagia. Six patients $(11.5 \%)$ presented with features of upper gastrointestinal bleed. Majority had significant weight loss at presentation.

Neoadjuvant therapy was given in only 6 patients (three each, belonging to Siewert types II and III). Among them, one each in both groups received radiotherapy in addition to chemotherapy. This is in contrast to recent evidence regarding the benefits of neoadjuvant therapy compared to upfront surgery for locally advanced junctional tumours in terms of improved $\mathrm{R}_{\mathbf{0}}$ resection rate, ability to achieve pathological complete response and better long term survival rates as per the MAGIC [11], ACCORD-07 [12], CROSS [13] and FLOT4 [14] randomised control trials. In our institution, neoadjuvant therapy is provided only for bulky tumours with doubtful resectability upfront as per the multidisciplinary tumour board policy. Hence, few patients received neoadjuvant therapy in this study.

Ten patients $(19.2 \%)$ were found to have evidence of metastatic disease in the form of surface liver metastasis (4 patients) and peritoneal metastasis (6 patients) during staging laparoscopy. Among the rest, 4 patients $(7.7 \%)$ were found to have unresectable tumours during surgery as a result of aortic infiltration in one patient, celiac axis infiltration in one patient and pancreatic body infiltration in two patients. Those with unresectable and metastatic disease underwent feeding jejunostomy and referred for palliative therapy.

Surgical procedures of choice for Siewert type I and III tumours are similar in both the Western and the Eastern literature [10]. Type I tumours are managed as esophageal cancers and type III tumours as gastric cancers. A significant proportion of surgeries are performed by minimally invasive techniques in the present era based on the availability of expertise. However, only two patients underwent minimally invasive surgery in this series.

All patients with resectable Siewert type I tumours underwent esophagectomy with cervical esophagogastric anastomosis. One patient underwent thoracoscopic-assisted esophagectomy and the rest underwent open transhiatal esophagectomy. One patient needed right thoracotomy to control bleeding from major vasculature.

All patients with operable Siewert type III tumours were managed by extended total gastrectomy. Two patients $(8.7 \%)$ required left thoracotomy and intrathoracic anastomosis for providing adequate in vivo proximal margin. Proximal margin was revised in 2 patients after frozen section analysis showed presence of tumour cells at the transected end. Five patients $(21.7 \%)$ underwent multivisceral resection - segmental colectomy $(\mathrm{n}=2)$, distal pancreato-splenectomy $(n=2)$ and Appleby procedure $(n=1)$

There is a wide variation in the surgical procedures performed for Siewert type II tumours in the literature [15]. In the western countries, transthoracic (Ivor-Lewis) esophagectomy with two field lymphadenectomy is the procedure of choice [16]. In the eastern countries, surgical procedures are based on the extent of esophageal involvement by the growth and the extent of planned lymph node dissection. As per Japanese guidelines, transhiatal extended total gastrectomy is recommended for tumours involving less than $3 \mathrm{~cm}$ of distal esophagus and transthoracic esophagectomy for those with greater length of esophageal involvement [17]. In a series of 485 patients with Siewert type II tumours, $75 \%$ of patients underwent extended gastrectomy, $19.4 \%$ patients underwent abdominothoracic / transhiatal esophagectomy and $5.6 \%$ patients underwent limited resection of distal esophagus and proximal stomach [6]

In our series, out of 10 patients with operable Siewert type II tumours, 7 patients $(70 \%)$ underwent extended total gastrectomy, 2 patients $(20 \%)$ underwent thoracoscopic-assisted esophagectomy and one patient $(10 \%)$ underwent transhiatal esophagectomy. One patient, who underwent extended total gastrectomy, needed right thoracotomy and intrathoracic anastomosis for providing adequate proximal margin. 
One patient underwent splenectomy for splenic vessel infiltration by the tumour.

On analysis of postoperative outcomes, complications were reported in 16 patients $(42.1 \%)$ who underwent definitive resection. Cardiopulmonary complications $(21.1 \%)$ were the most common cause for morbidity followed by anastomotic leak (10.5\%). Conduit necrosis was seen in one patient belonging to Siewert I group. Duodenal stump blow out was seen in two patients, one each belonging to Siewert II and III groups.

The mean length of postoperative hospital stay was 13 days overall and was comparable between the three groups. Reoperation was needed in 4 patients $(10.5 \%)$; one each for conduit necrosis and intrathoracic anastomotic leak, and in two patients for duodenal stump blowout. Inhospital mortality rate was $15.8 \%$, which is comparatively higher than that reported in most studies. A retrospective study from north India reported a mortality rate of $3.6 \%[18]$. The high perioperative mortality in our study may be attributed to advanced stage at presentation and borderline performance status (PS 2) of the patients. Sepsis and multiorgan dysfunction syndrome were the major causes of death.

On histological analysis, the mean tumour length was $5.4 \mathrm{~cm}$ and was comparable between the three groups. Most of the tumours were either moderately $(50 \%)$ or poorly $(42.1 \%)$ differentiated. One patient belonging to Siewert type III was found to have involved proximal margin. The NCCN guidelines recommend that atleast 15 lymph nodes should be removed for adequate nodal staging for esophagogastic junction tumours in patients who have not undergone neoadjuvant therapy [19]. However, in our study, the mean number of lymph nodes retrieved was 8 , and atleast 15 nodes were removed in only 6 patients (15.8\%).

Majority of the patients who underwent resection belonged to stage III $(47.4 \%)$ and stage IVA $(34.2 \%)$ as per the AJCC-8 stage grouping [4]. Among patients who were followed up periodically, 5 patients were detected to have recurrent disease. A significant number of patients were lost to follow up which may explain the lower documented recurrence rate compared to other studies which analysed patients in whom surgery was performed without neoadjuvant therapy.

\section{CONCLUSION}

Esophagogastric junction adenocarcinoma is an aggressive malignancy presenting as large, poorly differentiated tumours and at an advanced stage. Diagnostic laparoscopy helps to avoid unnecessary laparotomy in a significant proportion of patients. Aggressive surgery achieving margin negative resection after preoperative optimisation results in reasonable outcomes with acceptable perioperative morbidity and mortality. Intrathoracic anastomosis is feasible with acceptable risk of pulmonary complications. Multimodality treatment, including neoadjuvant therapy, should be the standard of care at all centres performing upper gastrointestinal surgery for optimal patient benefit.

\section{SOURCE OF SUPPORT}

None.

\section{CONFLICT OFINTEREST}

The authors declare that they have no conflict of interests.

$\begin{array}{ll}\text { ABBREVIATIONS } & \\ \text { AJCC } & - \text { American Joint Committee on Cancer } \\ \text { ANOVA } & \text { - Analysis of variance } \\ \text { CROSS } & \text { - Chemoradiotherapy for Esophageal Cancer } \\ \text { followed by Surgery Study } & - \text { Computed Tomography } \\ \text { CT } & - \text { 5-Fluorouracil, Leucovorin, Oxaliplatin, } \\ \text { FLOT } & \\ \text { Docetaxel } & \text { - Gastro Esophageal Reflux Disease } \\ \text { GERD } & \text { - Helicobacter pylori } \\ \text { H.pylori } & \text { - Japanese Gastric Cancer Association } \\ \text { JGCA } & \text { - Lymph Nodes } \\ \text { LNs } & \text { - Medical Research Council Adjuvant Gastric } \\ \text { MAGIC } & \text { Infusional Chemotherapy } \\ & - \text { National Comprehensive Cancer Network } \\ \text { NCCN } & \text { - Positron Emission Tomography } \\ \text { PET } & - \text { Preoperative therapy in Esophagogastric } \\ \text { POET } & \text { adenocarcinoma Trial }\end{array}$

-Performance status

- Microscopic negative resection margin

- Microscopic positive resection margin

- Standard Deviation

- Statistical Product and Service Solutions

- Union for International Cancer Control

- Video Assisted Thoracoscopic Surgery

- World Health Organisation

\section{REFERENCES}

1. In Williams, N., In O'Connell, P. R., and In McCaskie, A. (2018). The esophagus. Bailey and Love's Short Practice of Surgery, 27th Edition (pp. 1086-87). Boca Raton, FL: CRC Press.

2. Siewert, J. R., Feith, M., Werner, M., and Stein, H. J. (2000). Adenocarcinoma of the esophagogastric junction: results of surgical therapy based on anatomical/topographic classification in 1,002 consecutive patients. Annals of surgery, 232(3), 353.

3. Brierley, J. D., Gospodarowicz, M. K., and Wittekind, C. (Eds.). (2017). TNM classification of malignant tumours. John Wiley and Sons.

4. In Amin, M. B., In Edge, S. B., and American Joint Committee on Cancer, (2017). AJCC cancer staging manual 8 th ed. New York: Springer.

5. Japanese Gastric Cancer Association. (2018). Japanese classification of gastric carcinoma 2017 (The 15th edition). Tokyo: Kanehara-shuppan.

6. Feith, M., Stein, H. J., and Siewert, J. R. (2006). Adenocarcinoma of the esophagogastric junction: surgical therapy based on 1602 consecutive resected patients. Surgical oncology clinics of North America, 15(4), 751-764.

7. Straatman, J., Van Der Wielen, N., Cuesta, M. A., Daams, F., Garcia, J. R., Bonavina, L., and Van Der Peet, D. L. (2017). Minimally invasive versus open esophageal resection: three-year follow-up of the previously reported randomized controlled trial the TIME three-year follow-up of the previously repor
trial. Annals of surgery, 266(2), 232-236.

8. Cherian, J. V., Sivaraman, R., Muthusamy, A. K., and Jayanthi, V. (2007). Carcinoma of the esophagus in Tamil Nadu (South India): 16-year trends from a tertiary center. Journal of gastrointestinal and liver diseases: JGLD, 16(3), 245-249.

9. Tony, J., Kumar, S., and Thomas, V. (2008). Time trends and pathological profile of carcinoma lower oesophagus and gastro-oesophageal junction over the last 20 years-an experience from South India. Tropical Gastroenterology, 28(3), 113-116.

10. Hasegawa, S., and Yoshikawa, T. (2010). Adenocarcinoma of the esophagogastric junction: incidence, characteristics, and treatment strategies. Gastric cancer, 13(2), 63-73.

11. Cunningham, D., Allum, W. H., Stenning, S. P., Thompson, J. N., Van de Velde, C. J., Nicolson, M., ... and Smith, D. B. (2006). Perioperative chemotherapy versus surgery alone for resectable gastroesophageal cancer. New England Journal of Medicine, $355(1), 11-20$

12. Ychou, M., Boige, V., Pignon, J. P., Conroy, T., Bouché, O., Lebreton, G., Genève, J. (2011). Perioperative chemotherapy compared with surgery alone for resectable gastroesophageal adenocarcinoma: an FNCLCC and FFCD multicenter phase III trial. Journal of clinical oncology, 29(13), 1715-172

13. Shapiro, J., Van Lanschot, J. J. B., Hulshof, M. C., van Hagen, P., van Berge Henegouwen, M. I., Wijnhoven, B. P., and Cuesta, M. A. (2015). Neoadjuvant chemoradiotherapy plus surgery versus surgery alone for oesophageal or junctional chemoradiotherapy plus surgery versus surgery alone for oesophageal or junctional cancer (CROSS): long-term
oncology, 16(9), 1090-1098.

14. Al-Batran, S. E., Homann, N., Pauligk, C., Goetze, T. O., Meiler, J., Kasper, S., and Lindig, U. (2019). Perioperative chemotherapy with fluorouracil plus leucovorin, oxaliplatin, and docetaxel versus fluorouracil or capecitabine plus cisplatin and epirubicin for locally advanced, resectable gastric or gastro-oesophageal junction adenocarcinoma (FLOT4): a randomised, phase $2 / 3$ trial. The Lancet, 393(10184), 1948-1957.

15. Haverkamp, L, Seesing, M.F., Ruurda, J. P. Boone, J., and Hillegersberg, R. V. (2017) Worldwide trends in surgical techniques in the treatment of esophageal and gastroesophageal junction cancer. Dis Esophagus, 30(1), 1-7.

16. Giacopuzzi, S., Bencivenga, M., Weindelmayer, J., Verlato, G., and de Manzoni, G. (2017). Western strategy for EGJ carcinoma. Gastric Cancer, 20(1), 60-68.

17. Japanese Gastric Cancer Association. (2017). Japanese gastric cancer treatmen guidelines 2014 (ver. 4). Gastric cancer, 20(1), 1-19.

18. Parshad, R., Singh, R. K., Kumar, A., Gupta, S. D., and Chattopadhyay, T. K. (1999) Adenocarcinoma of distal esophagus and gastroesophageal junction: long-term results of surgical treatment in a North Indian Center. World journal of surgery, 23(3), 277.

19. Ajani, J. A., D'Amico, T. A., Bentrem, D. J., Chao, J., Corvera, C., Das, P., and Gerdes, H. (2019). Esophageal and esophagogastric junction cancers, version 2.2019, NCCN clinical practice guidelines in oncology. Journal of the National Comprehensive Cancer Network, 17(7), 855-883. 